\title{
Effect of Carboxymethyl Cellulose on the Properties of Ordinary Portland Cement
}

\author{
K. N. Farooque, ${ }^{* a}$ Z. Yeasmin, ${ }^{\text {a }}$ M. E. Halim, ${ }^{\text {b }}$ A. J. Mahmood, ${ }^{b}$ and M. Y. A. Mollah ${ }^{b}$ \\ ${ }^{a}$ IGCRT, BCSIR, Dhanmondi, Dhaka and ${ }^{b}$ Department of Chemistry, University of Dhaka, Dhaka, Bangladesh
}

\begin{abstract}
Organic Polymer carboxymethyl cellulose (CMC) (0.25, 0.50 and 1.5\% solution) was incorporated in Ordinary Portland Cement (OPC) and its effect on compressive strength, setting time, porosity, corrosive resistance, density and water absorbance have been studied. Organic polymer retards the setting time and a small increase in compressive strength was observed after 90 days for 0.5\% CMC. Addition of polymer has been found to be effective in improving the acid resistance of OPC. Interaction of CMC with OPC causes decrease in water absorption, porosity and chemically bound water. X-ray diffraction of OPC-CMC pastes after 4 months and 1 year display some new peaks as well as disappearance of few peaks showing interaction of CMC with hydrated cementitious pastes. Examination of microstructure reveals that fibre types of matters were formed in hardened cement paste.
\end{abstract}

Key words: Ordinary portland cement, Carboxymethyl cellulose (CMC), Compresssive strength, Porosity, XRD, SEM.

\section{Introduction}

Polymer modified mortar (PMM) and concrete (PMC) have received considerable attention for more than seventy years and research works have been carried out in many countries to develop it. PMM and PMC have become the dominant material in construction industry and recently used as popular construction material (Fowler, 1990; Ohama, 1997). Polymer modified concrete provides definite advantages over conventional concretes. Incorporation of polymer in a cementitious mix brings key advantages, particularly in terms of workability, durability, acid resistance due to its extremely low permeability (Singh et al., 2002). Gebaur et al., (1971) have indicated that addition of polymer improves the strength, corrosion resistance and other properties of cement mortar. Flexural and compressive strength (CS) of cement are increased with the addition of organic polymer (Birchall et al., 1981). The properties of the composites depend on the nature and quantity of polymer used. The effect of organic additives on the setting time, compressive strength and the other properties of cement have been reported by several workers (Propova et al., 2000). Many studies of the mechanical and durability properties of those composite material can be found in the literature (Joshua, 1997). Few cellulose based water soluble polymer such as hydroxymethyl cellulose (HMC), hydroxyethyl cellulose (HEC) and carboxymethyl cellulose have been reported (Kamal,

\footnotetext{
* Corresponding author: E-mail: ysom2002@yahoo.com
}

1995) as a high performance material for plastering and for underwater uses. In view of these considerations, the present study was undertaken and the effect of organic polymer on CS, setting time, porosity, density, water absorbance, chemically combined water and microstructure were studied.

\section{Materials and Methods}

\section{Materials}

i. Cement - Portland cement was supplied from CEMEX Cement Co. Ltd. The chemical composition of the cement is given in Table I.

Table I. Chemical Composition of OPC

\begin{tabular}{c|c}
\hline Constituents & wt. (\%) \\
\hline Loss on Ignition & 00.75 \\
$\mathrm{SiO}_{2}$ & 21.73 \\
$\mathrm{Al}_{2} \mathrm{O}_{3}$ & 06.30 \\
$\mathrm{Fe}_{2} \mathrm{O}_{3}$ & 02.98 \\
$\mathrm{CaO}$ & 64.04 \\
$\mathrm{MgO}$ & 01.76 \\
$\mathrm{Na}_{2} \mathrm{O}$ & 00.88 \\
$\mathrm{~K}_{2} \mathrm{O}$ & 00.57 \\
$\mathrm{TiO}_{2}$ & 00.12 \\
$\mathrm{SO}_{3}$ & 02.50 \\
Free lime & nil \\
\hline
\end{tabular}


ii. Carboxymethyl cellulose (CMC) - Analar grade CMC was used to prepare $0.25,0.50$ and $1.5 \%$ solution. Freshly prepared solution was used to prepare mortar sample.

iii. Sand - Sylhet sand (size -20mesh [0.85mm] +30mesh [0.60mm]) was used during mortar sample preparation.

\section{Methods}

i. Standard Vicat apparatus was used for the determination of setting time. CMC was dissolved in the required volume of water for preparing the cement paste. The setting time experiment was performed at $29 \pm 2{ }^{\mathrm{O}} \mathrm{C}$ following ASTM method.

ii. For the compressive strength test 2 X 2 X 2 inch cube sample (cement:sand=1: 2.75 and CMC solution) were cast in two layers following ASTM C 109 method. Six (6) cubes were prepared for each test. These were kept in $90 \%$ relative humidity ( $\mathrm{RH})$. After 24 hours, the samples were demoulded and again placed in 90\% RH until the day of testing. For the determination of other properties, test specimens were made following the method of Sing et al. 2002. Acid resistance was determined by weight loss method after immersion of the test specimens in 0.5 and $1.5 \mathrm{HCl}$ solutions. Chemically combined water was determined from the weight loss after igniting the test specimen in a muffle furnace at $1000^{\circ} \mathrm{C}$ for 2 hours.

iii. X-ray diffractometer (XRD) Model-JDX-8PJEOL, Philips using $\mathrm{CuK} \alpha$ radiation with Ni filter was used for phase analysis. Scanning Electron Microscope (SEM) Model SEM S 2600N, Hitachi was used for the evaluation of microstructure. Paste sample was prepared incorporating $\mathrm{CMC}$ solution in cement and cured for 60 days for XRD and SEM studies. Intensity and d-values were compared with the values available in the data book of "Selected Powder Diffraction Data for Minerals".

iv. Chemical analysis involves dissolution of cement in powder form and subsequent analysis by gravimetric method (ASTM). Iron oxide was determined by UVspectrophotometer.

\section{Results and Discussion}

\section{Compressive strength (CS)}

The results of the CS tests are shown in Fig. 1. The incorporation of organic polymer has a distinct behaviour towards the development of strength of OPC. Initially the incorporation of 0.25 and 0.5 percent CMC lower the CS value of Polymer Cement Composition (PCC) after 7-days and 14days but gradually the PCC starts gaining strength after 120 days and continues up to 365 days. Roy et. al., 1973 reported that organic set retarders increase the strength of the cement at late curing ages. The development of strength depends on the nature and amount of additive and $\mathrm{W} / \mathrm{C}$ ratio (Paillere et. al., 1975). When 1.5\% CMC was used in PCC, a decrease in CS was observed after 7 and 28 days compared to OPC and other two PCC (0.25\% and 0.5\%). Therefore tests were not carried out after 28 days for $1.5 \% \mathrm{CMC}$. The strength of the PCC is dependent on the total porosity and particularly the pore size distribution. Present investigation reveals (Table III) that the porosity of the PCC decreases when 0.25 and $0.5 \%$ CMC was incorporated in OPC but

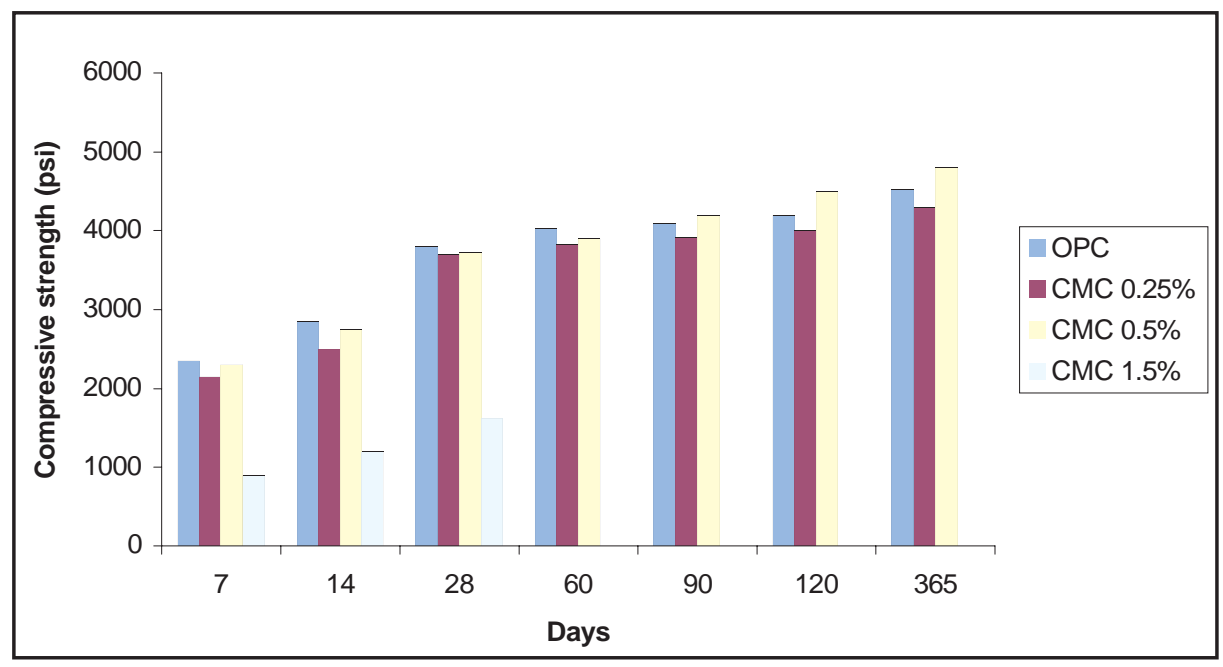

Fig. 1. Effect of CMC on the compressive strength of OPC 
porosity increases when CMC concentration was $1.5 \%$. The study indicates that there is a certain limit of addition of polymer in the system as 1.5 percent CMC addition significantly decreases the compressive strength. According to semi-empirical model by Mikhail et al., 1984 which reveals that the strength of the PCC is a function of the volume of cement paste and the initial porosity of the sample, i.e. its residual porosity, the final strength of the composite cement is independent of the mechanical properties of the polymer. The higher strength developed when 0.5\% CMC was incorporated might be due to pore-filling at the interface of cement-polymer which is the weaker point of the cementitious matrix. These inherent weak points in the cement mortar/concrete are due to heterogeneous components present in cement. If the interface is free of voids/pores, cement polymer bonding will be strong (Maiti et al.,1995). However, it is generally accepted that a polymer, in the present investigation CMC is also a factor for better strength because of stronger cohesive forces within itself. The decrease in compressive strength when CMC concentration was increased from $0.5 \%$ to $1.5 \%$ may be high concentration of CMC (1.5\%) somehow hindering the formation of basic microstructure, responsible for CS, that consists of C-S-H needles and C-S-H leafs, platy calcium hydroxide and ettringite crystals. The decrease in CS can also be explained by the fact that soft polymer might be present in the hardened cement which has the same effect as pores (Skalny et al.,1997).

\section{Setting time}

In general organic polymer retards the setting of cement and concrete. The initial and final setting time of cement and PCC are shown in Table II. The hydration of tricalcium aluminate is responsible for the setting of cement. It is evident from the data that the initial and final setting time has been prolonged due to addition of 0.5 and 1.5\% CMC which indicate that CMC acts as a set retarder.

Table II. Effect of CMC on the setting time of OPC

\begin{tabular}{c|c|c}
\hline Experiment & $\begin{array}{c}\text { Initial setting } \\
\text { (hr-min) }\end{array}$ & $\begin{array}{c}\text { Final setting } \\
\text { (hr-min) }\end{array}$ \\
\hline OPC & $1 \mathrm{hr}$. & $1 \mathrm{hr} .24 \mathrm{~min}$. \\
OPC (0.5\% CMC) & $2 \mathrm{hr} .45 \mathrm{~min}$. & $4 \mathrm{hr} .3 \mathrm{~min}$. \\
OPC (1.5\% CMC) & $3 \mathrm{hr} .50 \mathrm{~min}$. & $4 \mathrm{hr} .20 \mathrm{~min}$ \\
\hline
\end{tabular}

It is the characteristic property of the functional group in the organic compound, its nature, chain length, etc which affects the cementitious properties of cement in which it is mixed. The mechanism of set retardation has been reported (Skalny et al.,1997) which may be primarily due to retarding of the hydration of $3 \mathrm{CaO} . \mathrm{SiO}_{2}$ through the chemisorption of organic molecule on to $\mathrm{Ca}(\mathrm{OH})_{2}$ nuclei. Adsorption on to the initial hydration products of tricalcium aluminate can also retard further hydration (Singh et al., 1989). The retardation process may also be due to the chemical interaction between the hydrating silicates, aluminate and organic compounds to yield amorphous materials in the cement matrix. The chelates of organic salts of calcium or aluminium formed during hydration are interspersed in the crystalline mass. They are quite insoluble and not removable from the stiffened mass of organic set retarding agent containing $\mathrm{HC}-\mathrm{OH}$ group in their molecule, retard the rate of absorption of $\mathrm{H}_{3} \mathrm{O}^{+}$ ions on cement surface and slow down the setting reactions (Skalny et al., 1997).

\section{Corrosive resistance}

Sixty (60) days cured samples were used for corrosion studies. Corrosion tests were carried out by weight loss method in $\mathrm{HCl}$ acid media of different concentration $(0.5,1.0,1.5 \mathrm{M}$ $\mathrm{HCl}$ ). Table III shows the variation of wt. loss in $\mathrm{HCl}$ acid solution of different concentration. The percent wt. loss of the cement mortar sample and CMC incorporated mortar samples were observed.

Table III. Corrosion of Polymer Cement Composite

\begin{tabular}{l|c|c|c}
\hline Experiment & \multicolumn{3}{|c}{ Loss wt. \% } \\
\hline HCl (M) & OPC \% & $0.25 \%$ CMC & $0.5 \%$ CMC \\
\hline 0.5 & 2.41 & 2.38 & 2.20 \\
1.0 & 4.40 & 2.68 & 2.50 \\
1.5 & 6.79 & 3.32 & 4.35 \\
\hline
\end{tabular}

The test result indicates that CMC is effective to some extent to inhibit corrosion of the mortar samples when compared with reference OPC. The results show that for $0.5 \mathrm{M} \mathrm{HCl}$ solution there is no significant difference in the wt. loss for the mortar specimens incorporating CMC after 7 days. With increase in the concentration of $\mathrm{HCl}$, the polymer cement composite was found to be better acid resistant than OPC. Chandra et. al., 1987 has described the $\mathrm{HCl}$ attack as a reaction occurring in layers forming distinct zone and $\mathrm{HCl}$ dissolution of $\mathrm{Ca}(\mathrm{OH})_{2}$ is well known. The acid resistance of PCC may be due to the reduced porosity which was also investigated by Gebauer et al., 1971. It seems that in polymer mod- 
ified cements, the pores are filled with polymer or reactant products which reduce the porosity and capillary systems and resist corrosion. The $\mathrm{HCl}$ can attack the aluminates of cement phases which can form monochloroaluminate. They also transform hydrated calcite fibre into a more porous reticular network. The development of porosity in cement is probably due to leaching out of this monochloroaluminate (Ohama, 1997).

\section{Porosity, Density, Water Absorbance and Chemically Bound Water of Polymer Cement Composite}

The test results in Table IV indicate that the incorporation of CMC increased the bulk density, thereby decreasing the apparent porosity of the test specimens for CMC concentration up to $0.5 \%$. The effect of polymer addition results in a decrease in the porosity, water absorbance of the PCC, although higher concentration of CMC (1.5\%) caused an increase in the porosity of the composite cement. It is evident from this investigation that there is an optimum concentration of CMC at which the maximum density can be obtained. Decrease in the chemically combined water also indicates a retardation effect on the hydration of OPC when CMC concentration increased. During hardening of mortar, polymer can form another network in the material, which fills up pores in cement matrix and improves the bonding between aggregate and cement paste ( Fichet et al., 1998; Wu et al., 2002) and reduce porosity.

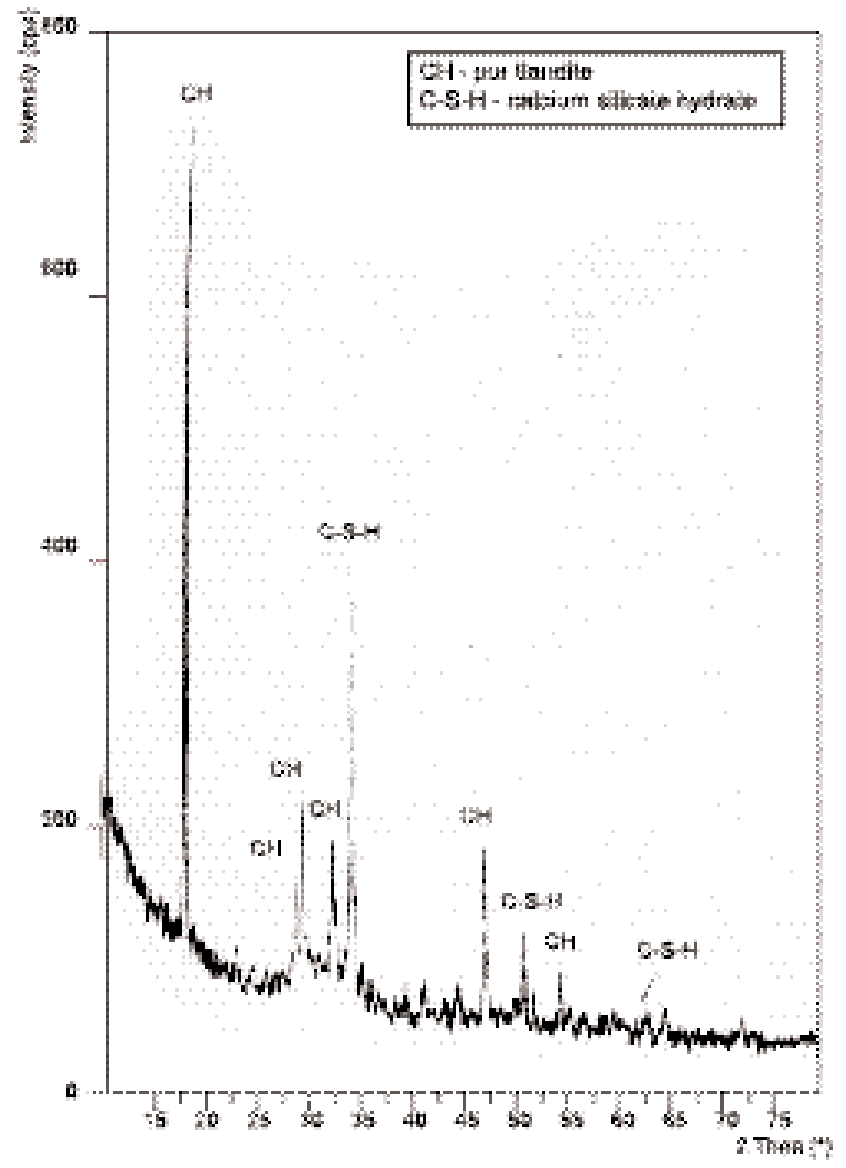

Fig. 2. X-ray diffractogram of 4 months old hydrated OPC paste

Table IV. Effect of CMC on the properties of polymer cement composite

\begin{tabular}{l|c|c|c|c}
\hline Polymer \% (CMC) & Density (g/cc) & Porosity \% & Chemically bound $\mathrm{H}_{2} \mathrm{O} \%$ & Water absorbance \% \\
\hline 0.00 & 2.15 & 17.00 & 10.75 & 7.60 \\
0.25 & 2.18 & 15.42 & 10.28 & 6.99 \\
0.5 & 2.42 & 13.35 & 9.75 & 5.95 \\
1.5 & 2.10 & 18.00 & - & 8.20 \\
\hline
\end{tabular}

\section{XRD Observation}

The effect of CMC on the hydrated phases of cement was observed by analysing relative intensities of peaks in the XRD. The results are shown in Fig. 2, 3, 4 and 5. When 4 months old hydrated OPC paste (Fig.2) was compared with 4 months old OPC-CMC (0.5\% and 1.5\%) pastes (Fig 4 and 5) small change in the diffractogram was observed. In the 4 months old OPC-CMC (0.5\%) paste 3 new peaks appeared at angle $2 \theta(0.63,0.47,0.31)$ with corresponding d-spacing (2.62, 2.18 and 1.75) $\AA$ which remain unidentified. It is interesting to note that in the 4 months old hydrated OPC-CMC
(1.5\%) paste (Fig. 5) the peak at angle $2 \theta 0.63$ with corresponding d-spacing 2.62 disappeared but it was present in OPC-CMC (0.5\%) and a shifting of peak was observed at $2 \theta$ 0.23 instead of $2 \theta 0.31$ in OPC-CMC (0.5\%). When 1 year old hydrated OPC paste (Fig. 3) was compared with 1 year old hydrated OPC-CMC (Fig. 6 and 7) the diffractograms again showed similar characteristics such as appearance of new peaks and disappearance of some peaks as well as shifting of peaks. In the 1 year old hydrated OPC-CMC $(0.5 \%)$ paste the new peaks appeared are at angle $2 \theta(25.75,26.20$, 28.22 and 56.67) with corresponding d-spacing (3.45, 3.39, 3.15 


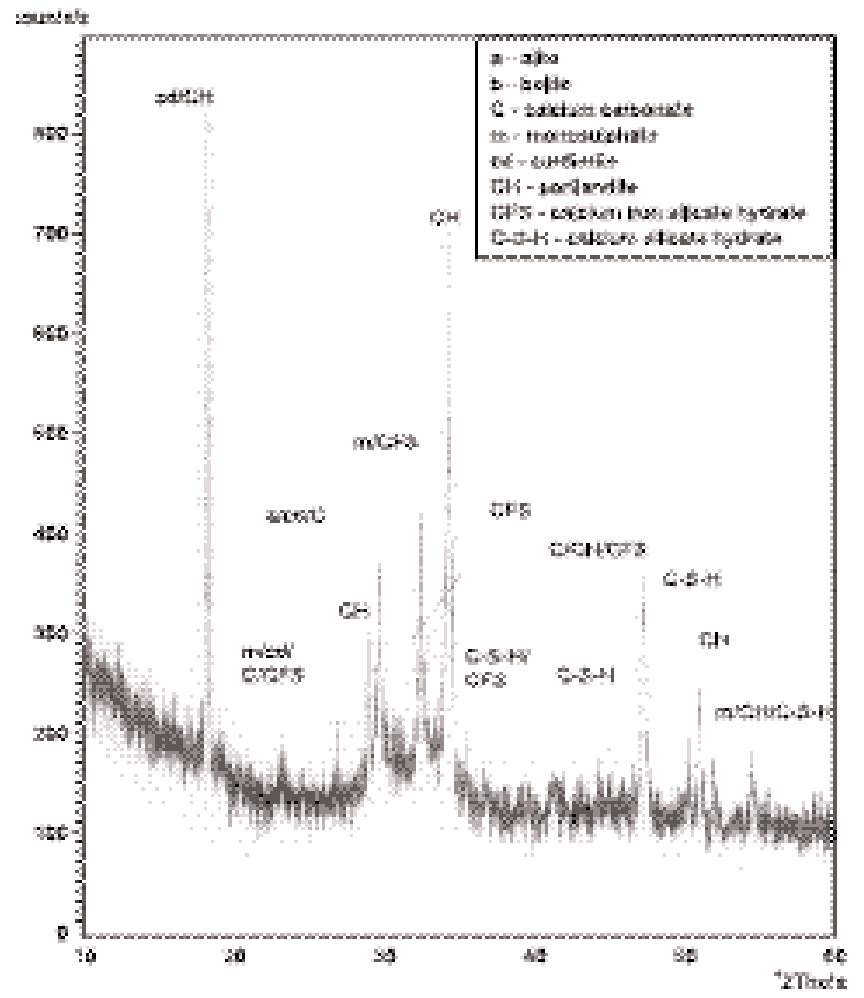

Fig. 3. X-ray diffractogram of 1 year old hydrated OPC paste

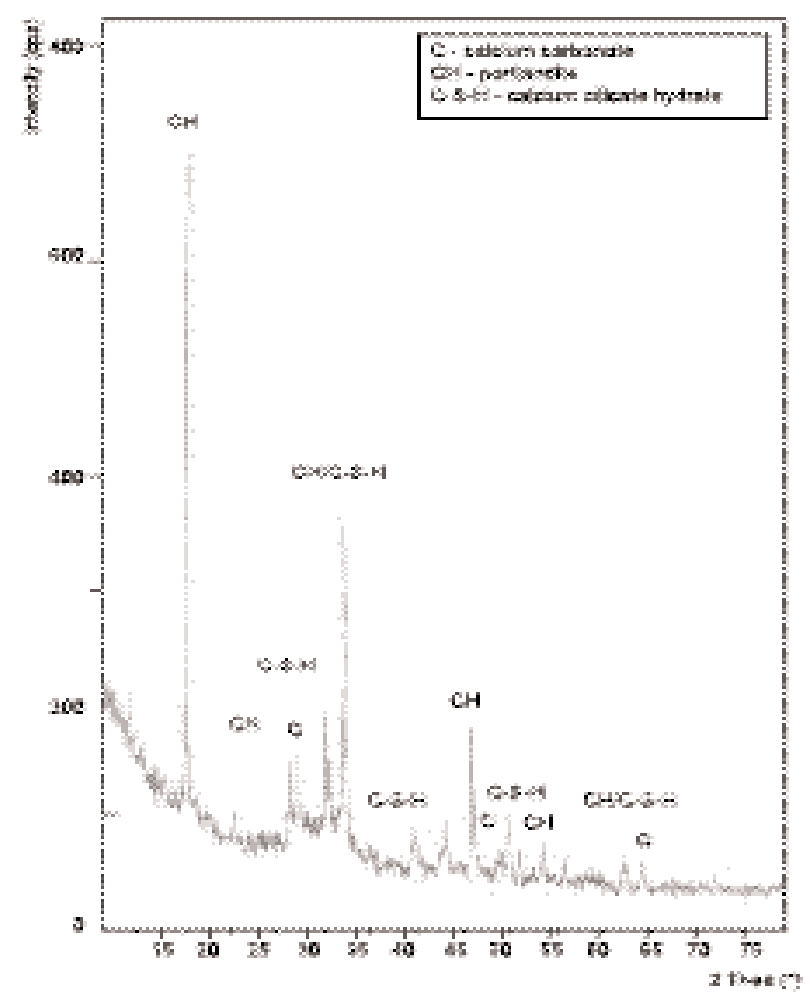

Fig. 4. X-ray diffractogram of 4 months old hydrated OPC-CMC (0.5\%) paste

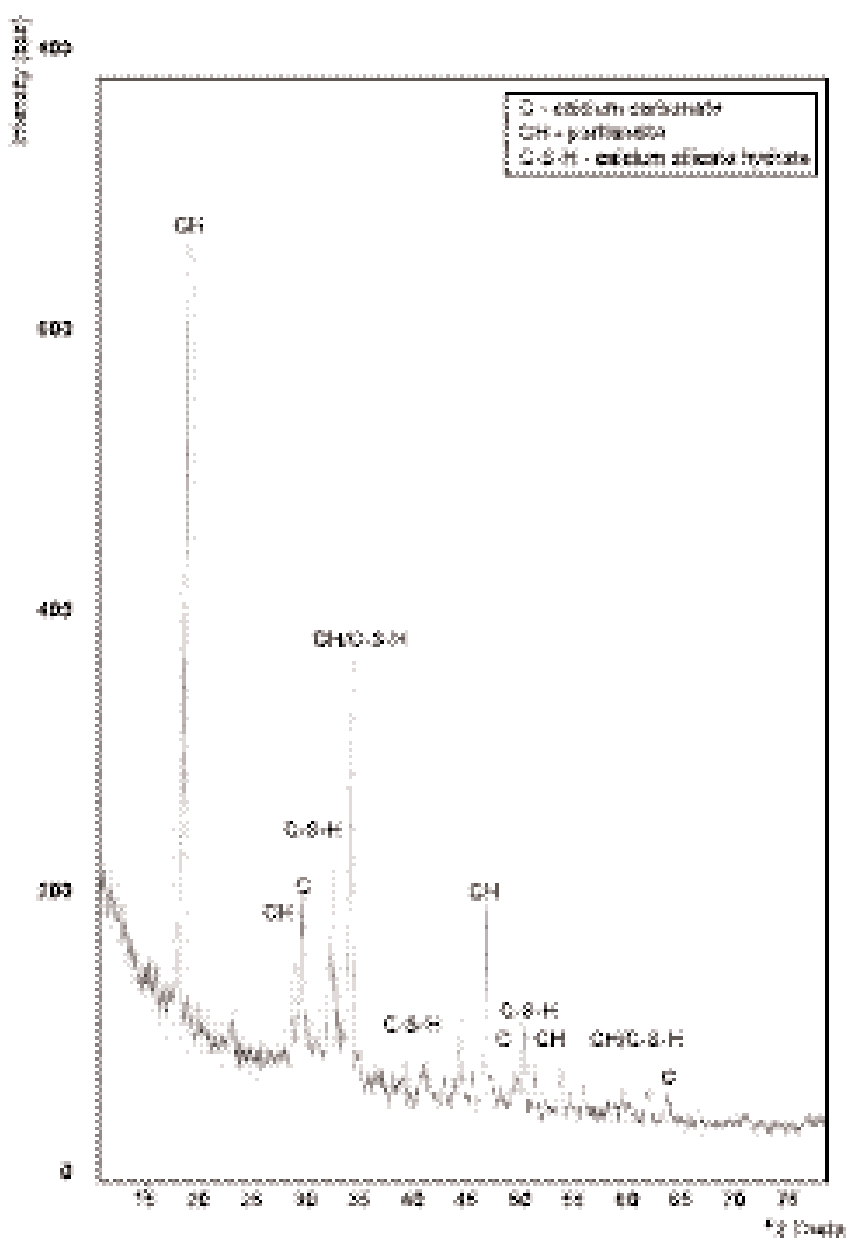

Fig. 5. X- ray diffractogram of 4 months old hydrated OPC-CMC (1.5\%) paste

and 1.62) $\AA$. The peaks which were present in 1 year old hydrated OPC paste but absent in CMC (0.5\%), are at angle $2 \theta$ (12.34, 33.87, 34.45 and 44.20) with corresponding dspacing (7.16, 2.64, 2.60 and 2.04) $\AA$. When concentration of CMC was increased to $1.5 \%$ two peaks at angle $2 \theta$ (16.19 and 34.54) with corresponding d-spacing (5.46 and 2.59) $\AA$ appeared which were not present in OPC-CMC (0.5\%). The peaks which are now absent are at angle $2 \theta$ (26.20, 28.23, 30.26, 35.23, 45.87 and 56.67) with corresponding d-spacing (3.39, 3.15, 2.95, 2.54, 1.97 and 1.62)A. Careful examination of the diffractograms clearly indicates retardation of hydration in presence of CMC. Although this retardation effect was not observed in 1 year old OPC-CMC (0.5\%) paste when compared with 1 year old hydrated OPC paste, but it is clearly evident in the 1 year old hydrated OPC-CMC (1.5\%) paste. The decrease in relative intensity of $\mathrm{CH}$ peak in OPC-CMC (1.5\%) reveals the retardation effect. The appearance of unhydrated alite, belite and ferrite phases in 


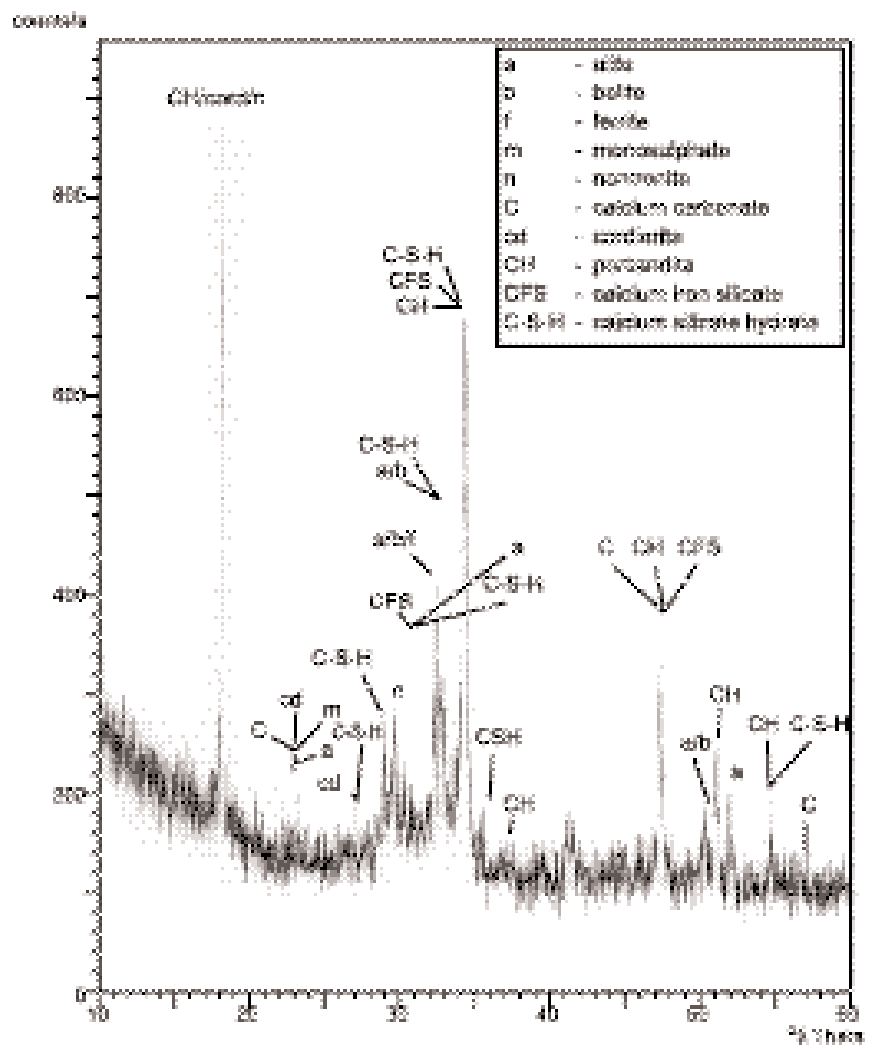

Fig. 6. X-ray diffractogram of 1 year old hydrated OPC-CMC (0.5\%) paste

OPC-CMC (1.5\%) (Fig. 7) is also an indication of this retarding effect (Singh et. al., 2002). Therefore the results clearly indicate that some interaction between hydrated OPC and CMC might have occurred when CMC was incorporated in OPC. The major phases detected are shown in the XRD pattern (Fig. 4-7). The main phases identified in all these pastes comprise $\mathrm{CH}$, C-S-H, cordierite (magnesium aluminium silicate), $\mathrm{CaCO}_{3}$, nontronite (calcium aluminium iron silicate), krischsteinite (calcium iron silicate), tobermorite (calcium silicate hydrate) and monosulphate. The study clearly indicates that organic additive influences the hydration of cement because of chemical interaction. The ions or molecules formed during the hydration of cement are the controlling factor to the formation of OPC-CMC products. There were few unidentified peaks in OPC-CMC $(1.5 \%)$ hydrated paste. The appearance of the new phases can be accounted for the increase in the CS of OPC-CMC (0.5\%) hydrated specimen. It is very difficult to identify any new phases that might have formed when CMC was incorporated because cement is a very heterogeneous and complex system and there could be some overlapping of phases as well.

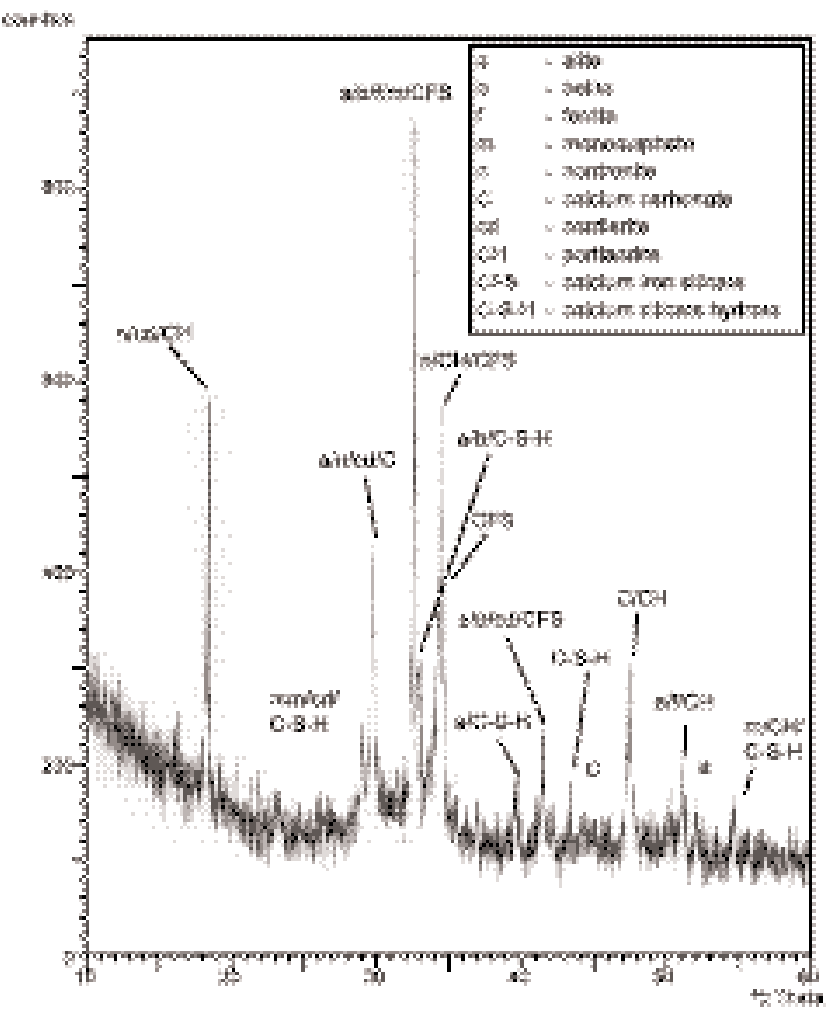

Fig. 7. X-ray diffractogram of 1 year old hydrated OPC-CMC (1.5\%) paste

\section{Microstructure of Polymer Cement Composite}

The microstructure of CMC (Fig. 8) and OPC-CMC hydrated paste of 28 days $(0.5,1.5 \%)$ is shown in Fig. 9 and Fig. 10 respectively. The microstructure of CMC shows its filmy nature. The 28 days hydrated sample shows the presence of filmy matter in the OPC-CMC paste, the filmy matters are more present in the sample containing 1.5\% CMC. The films look like sheet which fills the pores. In the OPC-CMC (1.5\%) hydrated paste (Fig. 10), though some films had made the hydrated structure denser, but they still shows their own filmy form (Fig. 10). The denser hydrated paste is divided into small compartments as evident from the round shaped character. In the 1-year hydrated paste (Fig. 11), (Fig. 12) though the filmy nature is evident but the structure looks more compact. The increase in the compressive strength of PCC $(0.5 \%)$ can be attributed to the distribution of polymer particles in the hardened cement as a reinforcing particle through film formation that might have occurred in the cement matrix. 


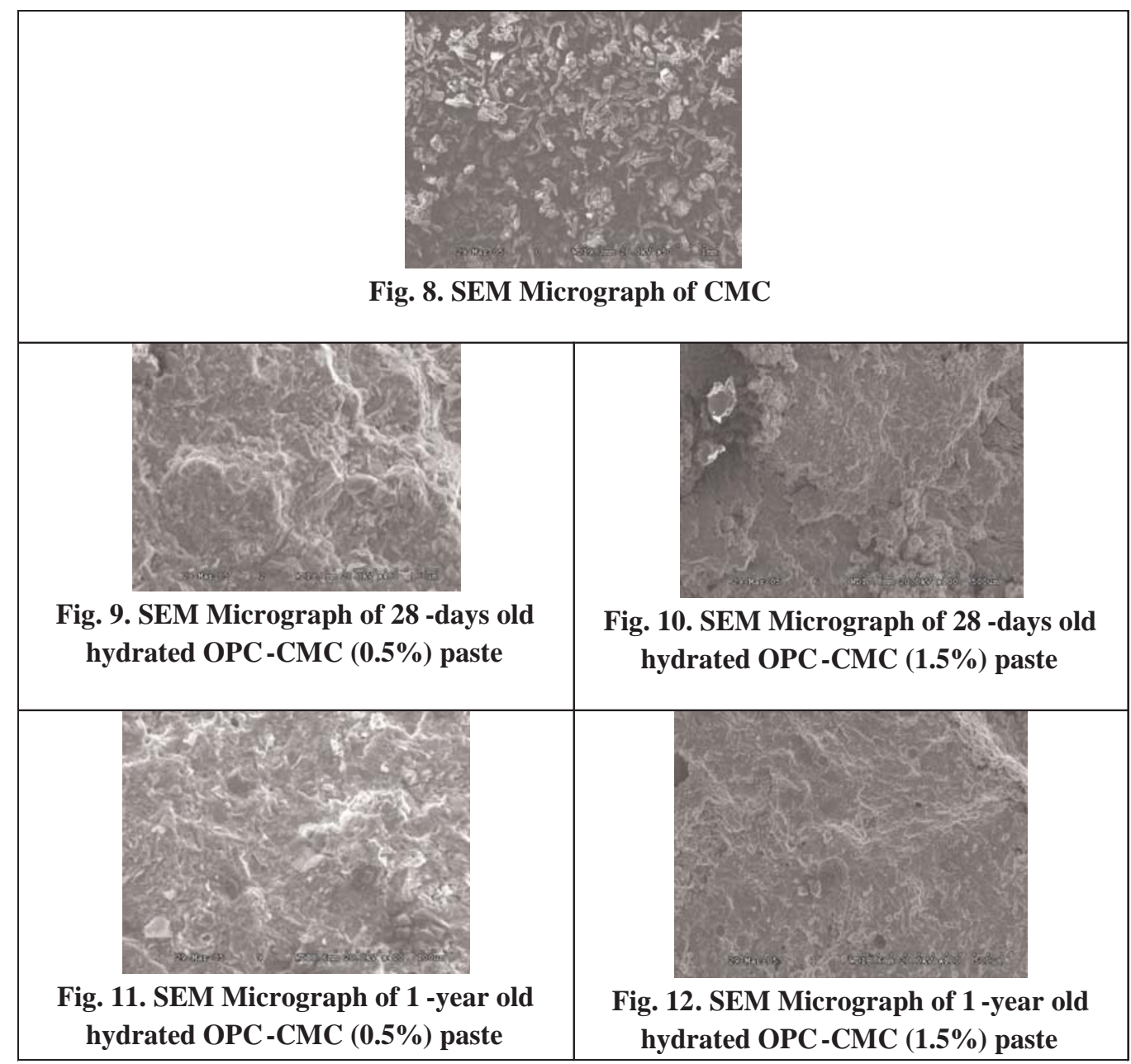

\section{Conclusion}

The present study indicates that polymer addition in OPC is effective for further improvement of CS, water resistance, reduced porosity and acid resistance, though an increase in setting time was found. The XRD and SEM observation indicate that organic polymer (CMC) influences the hydration of $\mathrm{OPC}$ and microstructure.

\section{References}

Birchall J. D., Howard A. J. and Kendall K. (1981) Flexural Strenth and Properties of Cement, Nature, 289: 388-89.

Chandra S. and Flodin P. (1987) Interaction of Polymer and Organic Admixtures on Portland Cement Hydration, Cem. Concr. Res., 17: 875-890.

Fichet R. O., Gauthier C., Clamen G. and Bock P. (1998)
Microstructural Aspects in Polymer-Modified Cement, Cem.Concr.Res., 28(12): 1687-1693.

Fowler D. W. (1990) Polymers in Concrete, Proceedings of the 6th International Congress on Polymers in Concrete, Y. Huang, $\mathrm{K} \mathrm{Wu}$ and Z. Chen., Eds., International Academic Publsihers : Beijing, 10-17.

Gebauer J. and Coughlin R. W. (1971) Preparation, Properties and Corrosion Resistance of Composites of Cement Mortar and Organic Polymers, Cem. Concr. Res., 1: 187-210.

Joshua, B. K. (1997) Polymer Modified Concrete: Review, J. Mater. Civil. Eng., 85: 92

Khayat K. H. (1995) Frost Durability of Concrete Containing Viscosity Modifying Admixtures, ACI Mater J., 92(6): 625 - 633 
Maiti S. and Kirtanea K. R. A. (1992) Non Destructive Method for Testing of Mechanical Properties of Polymer Impregrated Concrete, Indian Journal of Technology, 30: 39- 42.

Mikhail R. S., Mousa A. M., Enein S. A. and Maries M. S. (1984) Compressive Strength Versus Residual Porosity in Polymer Impregnated Cement Pastes, Cem. Concr. Res. 14: 25-30

Paillere A. M. (1975) Application of Admixtures in Concrete, 1st Edition, E \& FN Spoon, London, pp 3940 .

Popova A., Geoffroy G., Renou-Gonnord M. F.,Faucon P. F. and Gartner E. (2000) Interactions Between Polymeric Dispersants and Calcium Silicate Hydrates, J. Am. Ceram. Soc. 83(10): 2556-60.

Roy M. D. and Gouda R. G. (1973) Porosity-Strength Relation in Cementitious Materials with Very High Strengths, J. Am. Ceram. Soc. 56(10): 549-50.

Sakai E. and Sujita, J. (1995) Composite Mechanism of Polymer modified Cement, Cem. Concr. Res., 25(1): 127-135.
Selected Powder Diffraction Data for Mineral, 1974 by Joint Committee of Powder Diffraction Standards, USA, First Edition.

Singh N. B. and Singh A. K. (1989) Effect of Melamine on the Hydration of White Portland Cement, Cem. Concr. Res., 19: 547-553.

Singh V. K., Khatri S. D. and Singh R. K. (2002) Hydration and Some Other Properties of Polyethylene Glycol Modified Cement Products, Indian Ceramic Society, 61(4): 152-161

Skalny J. and Tadros M. E. (1997) Retardation of Tricalcium Aluminate Hydration by Sulphates, J. Am. Cer. Soc., 60(3-4): 174-175.

Wu K. R., Zhang D. and Song J. M. (2002) Properties of Polymer Modified Cement Mortar Using PreEnveloping Method, Cem. Concr. Res., 32: 425-429.

Ziyi L. and Xihui Z. (2000) The Waterproofing Characteristics of Polymer Sodium Caboxymethyl-cellulose, Cement and Concrete Research, 30: 22-231.

Received : March 29, 2008;

Accepted : August 06, 2009 